\title{
EL RECURSO DE AMPARO ECONÓMICO: UNA TENDENCIA JURISPRUDENCIAL PELIGROSAMENTE REDUCCIONISTA
}

\author{
Domingo Hernández Emparanza ${ }^{1}$ \\ Profesor Universidad de Talca \\ dohernandez@utalca.cl
}

\section{LA SENTENCIA “GONZÁlez IlLANes": UN NUEVO HITO JURISPRUDENCIAL}

El 1 de abril de 2009 la E. Corte Suprema resolvió el recurso de amparo económico deducido por don Sergio Luis González Illanes contra la I. Municipalidad de Santiago, ${ }^{2}$ dirigido a obtener el alzamiento de la clausura decretada por ésta respecto de su taller de reparación de vehículos motorizados.

El fallo es digno de análisis por varias razones. La primera y tal vez más importante: porque revierte una jurisprudencia al parecer ya consolidada en torno al alcance del RAE., que la jurisprudencia del máximo tribunal había considerado idóneo para la defensa del principio de la libertad económica en su más amplia expresión, comprensiva de la protección contra los excesos cometidos por el Estado y sus organismos en materia económica y que, en esta nueva orientación, se estima sólo procedente respecto de la garantía constitucional del numeral $2^{\circ} \mathrm{del}$ artículo 19 de la Carta Fundamental.

Pero también este pronunciamiento se sitúa en una perspectiva conservadora en la óptica de lo que son las atribuciones de que el órgano jurisdiccional se encuentra dotado para resolver este arbitrio procesal. Confirma en tal sentido una tesitura ya tradicional en el sentido que la jurisdicción no se encuentra habilitada para "adoptar providencias cautelares prontas e inmediatas para brindar resguardo

\footnotetext{
${ }^{1}$ Abogado. Doctor en Derecho. Profesor de Derecho Administrativo de la Facultad de Derecho de la Universidad de Talca y del Centro de Estudios de Constitucionales de Chile. Abogado Integrante de la Excma. Corte Suprema.

${ }^{2}$ SCS. en RAE. “Sergio Luis González Illanes con Municipalidad de Santiago”, Rol No 501-09, de 1.04.2009 (Ministros Sres. Oyarzún (redactor), Carreño, Pierry, Sra. Araneda y Sr. Brito, con voto en contra de la Sra. Araneda y prevención del Sr. Brito), que revocó la sentencia de primera instancia de la CAS. (de 9.12.2008) y rechazó el recurso.
} 
al afectado, como sí se establecen en el artículo 20 de la Constitución Política tratándose del recurso de protección" (considerando $12^{\circ}$ ).

Finalmente, arguye el sentenciador que la norma del inciso $1^{\circ}$ del artículo único de la Ley No 18.971, que faculta a cualquier persona para denunciar las infracciones al artículo 19, No 21 de la Constitución Política, no es clara en su sentido, por lo cual propone recurrir, para desentrañar su auténtico significado, a las reglas de interpretación complementaria que establece el Código Civil, en el párrafo $4^{\circ}$ de su Título Preliminar.

Todas estas orientaciones reflejan planteamientos doctrinarios marcadamente formalistas, claramente desconocedores de las visiones extensivas y garantistas de los derechos postuladas en el Derecho Internacional y aun alejadas de las técnicas y métodos de interpretación característicos del Derecho Público, que en nada se avienen con los criterios hermenéuticos del Código Civil.

Son precisamente estos parámetros los que nos permitirán una mirada distinta, susceptible de suscitar en el lector una reflexión crítica en torno a una tesis jurisprudencial cuya generalización amenaza con privar a los particulares de un remedio procesal que, de mantenerse en su actual diseño, declinará inexorablemente en su eficacia.

2. El RAE. SÓlO PROTEGE LA GARANTÍA CONSTITUCIONAL DEL ARTÍCULO 19, INCISO 20 DE LA CPR.: ¿UNA INVOLUCIÓN INTERPRETATIVA?

La doctrina y la jurisprudencia han estado profundamente divididas, desde la instauración de este denominado "recurso" -pero que en ortodoxia procesal es una acción dirigida a hacer efectivo un derecho- en torno de su ámbito de cobertura.

Se pueden distinguir dos etapas, según cual sea el punto de vista prevaleciente en orden a su alcance. ${ }^{3}$

\subsection{Etapa inicial (1990-1995): interpretación restrictiva}

El bien jurídico tutelado por la vía de esta acción es el orden público económico, frente a los excesos o desbordes del Estado empresario, vale decir, sólo resguarda el inciso $2^{\circ}$ del artículo 19 de la Carta Fundamental. Es la posición inicialmente sostenida por nuestros tribunales, en distintas sentencias del período indicado.

\footnotetext{
${ }^{3}$ Destacan, en la dirección indicada, los fallos: Enrique Llano Macuer con SEREMI Metropolitano de Transportes, CS., 30.04.1991; Asociación Gremial de Armadores Artesanales VIII Región con Presidente de la República, Rol 738-92, CAS., 6.05.1992 (desistido en 2a instancia el 14.05.1992) y Cía. Minera Santa Laura con Municipalidad de San Bernardo, CS., 20.11.1995.
} 
El recurso de la especie, se dijo, "ha sido establecido para resguardar el orden público económico cuando el Estado y sus organismos entran a desarrollar, sin contar con una autorización legal especial, actividades empresariales o participando en éstas, hecho que no ocurre en la especie..."4. Y "no se relaciona con el inciso $1^{\circ}$ (del artículo 19 , No 21) que protege el derecho a desarrollar cualquier actividad económica que de conformidad a lo establecido en el artículo 20 de la Carta Fundamental, está resguardado por el recurso de protección, por tanto, en la realidad, es una acción con tal carácter"s.

\subsection{Etapa intermedia (1995-2008): interpretación amplia}

La acción de amparo económico -sostiene la jurisprudencia uniforme de la E. Corte Suprema, durante más de una década- protege el contenido de los dos incisos del artículo 19 de la Carta Fundamental.

"Desde Pullinque S.A. con Endesa, de fecha 19 de marzo de 1992, hasta Asociación de Importadores y Exportadores de Vino con Presidente de la República y Ministro de Agricultura, de fecha 26 de mayo de 1996, la Corte Suprema ha admitido la procedencia del recurso por infracciones al derecho a desarrollar cualquier actividad económica, sea ésta cometida por el Estado o por particulares".

Bástenos complementar en orden a que esta tesitura siguió manteniéndose, sin alteraciones, hasta el fallo materia de este comentario.

\section{3. "González Illanes con Municipalidad de Santiago": punto inicial de una inflexión jurisprudencial}

Efectivamente, este veredicto marca el hito inicial de una nueva tendencia, que implica el retorno a posiciones mantenidas en la que hemos denominado etapa inicial de la jurisprudencia relativa al alcance del instituto procesal que nos ocupa. Decimos que es un pronunciamiento emblemático porque su contenido ha venido a ser reproducido íntegra o al menos parcialmente en todas las decisiones

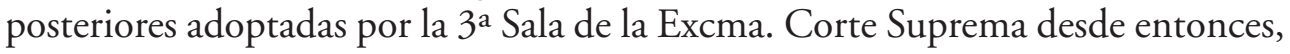
sin ningún quiebre, pero con un voto disidente sistemático de la Ministra Sra. Araneda ${ }^{7}$.

\footnotetext{
${ }^{4}$ SCS. Cía Minera... (cit.), consid. 6º

${ }^{5}$ SCAS. Enrique Llanos... (cit.), consid. 90.

${ }^{6}$ Fermandois Vöhringer, Arturo, en Informe Constitucional No 1.321, de 26.07.1996, p. 3.

${ }^{7}$ La tesis se presenta en dos versiones: la original, que repite en forma textual el contenido de la sentencia materia de este comentario, incluso la prevención del Ministro Sr. Haroldo Brito C., al que se adiciona, desde el 29.04.2009 el voto disidente de la Ministra Sra. Sonia Araneda B., cada vez que ésta integra la $3^{\text {a }}$
} 
Al cabo de una prolongada reflexión, concluye el fallo en el sentido de "la inidoneidad del llamado recurso de amparo económico para salvaguardar la garantía fundamental reconocida en el artículo 19 No 21 inciso $1^{\circ}$ de la Carta Fundamental" (considerando 13\%).

Luego de transcribir la norma del artículo único de la Ley No $18.971^{8}$, discurre que si bien ésta "denota claridad en su tenor literal, no ocurre lo mismo con su sentido, que resulta ambiguo en cuanto a la finalidad que tuvo en vista el legislador al establecer la situación que ha dado pábulo a la divergencia de opiniones susten-

Sala de la CS., y una transposición extractada, que desarrolla sólo los contenidos de las ponderaciones $8^{\text {a }}$, $10^{\mathrm{a}}, 11^{\mathrm{a}}$ y $12^{\mathrm{a}}$ del fallo modélico.

La versión desarrollada o amplia transcribe en forma prácticamente literal lo resuelto en "González Illanes". Cabe citar al respecto: "Celcon S.A. con Instituto Nacional de Normalización", Rol 1188-09, de 16.04.2009 (Ministros Sres. Oyarzún, Carreño, Pierry, Brito y A.I. Sr. Ruiz P., con prevención del Sr. Brito); "Rojas Alarcón, Claudio con Ministerio Público", Rol 739-09, de 29.04.2009 (Ministros Sres. Oyarzún, Carreño, Pierry, Araneda y Brito, con prevención de este último y voto en contra de la Sra. Araneda); "Jorge Monje y otros con Banco Santander", Rol 650-09, de 29.04.2009 (misma composición y votación anterior); "Ismael Ruiz Taruman y otros con Bernardo Gabriel Contreras Muñoz", Rol 1363-09, de 29.04.2009 (Ministros Sres. Oyarzún, Carreño, Araneda, Brito y A.I. Sr. Matriz, con voto disidente de la Sra. Araneda y prevención del Sr. Brito); "Felipe González Wodehouse con Municipalidad de Antuco", Rol 2537-09, de 27.05.2009 (Ministros Sres. Oyarzún, Carreño, Araneda y A.I. Sres. Chaigneau y Ruiz P., con prevención del Sr. Brito); "Elementos Industriales y Tecnológicos Limitada con Inspección Provincial de Trabajo de Calama", Rol 6125-09, de 29.10.2009 (Ministros Sres. Oyarzún, Dolmetsch, Carreño, Araneda y A.I. Sr. Ruiz P., con voto en contra de la Sra. Araneda); "Agrícola Magalys Werner con Juez del 20 Juzgado de Osorno y otro", Rol 1655-09, de 7.05.2009 (Ministros Sres. Oyarzún, Carreño, Araneda, Brito y A.I. Sr. Gorziglia, con la tradicional disidencia de la Sra. Araneda y prevención del Sr. Brito).

Un matiz registra la resolución en causa "Patricia del Carmen Cárcamo Bahamonde con Lidia del Carmen Bahamonde Bórquez", Rol 6346-09, de 27.01.2010 (Ministros Sres. Carreño, Araneda, Brito y A.I. Sres. Pozo y Hernández, el primero de los cuales adhiere a la tesis disidente de la Sra. Araneda).No obstante producirse dispersión de votos, se impuso la posición ya clásica de la Sala, al adherir el Sr. Brito a la mayoría, contra el voto de la Sra. Araneda y del A.I. Sr. Hernández, quienes estuvieron por entrar al fondo, atendida su inteligencia respecto del alcance amplio del art. 19.21 de la CPR.).

Por su parte, las decisiones asumidas en los casos siguientes, idénticas a las que antecede, adoptan un modelo más concentrado, limitándose a replicar, en lo sustancial, los fundamentos $8^{\circ}, 10^{\circ}, 11^{\circ}$ y $12^{\circ}$ de las sentencias antes mencionadas: "Patricia del Carmen Mora con I. Municipalidad de Calama", Rol 222-10, de 27.01.2010, (Ministros Sres. Carreño, Araneda, Egnem y A.I. Sres. Jacob y Ruiz P., con voto disidente de la Sra. Araneda); "Hotelera Rent a Home con I. Municipalidad de Providencia", Rol 6959-09, de 10.12.2009 (Ministros Sres. Oyarzún, Araneda, Brito y A.I. Sres. Matriz y Gorziglia, con disidencia de la Sra. Araneda y prevención del Sr. Brito); "Beatriz del Carmen Barrios Verdugo con Supermercado Korlaet de Calama", Rol 5971, de 10.09.2009 (Ministros Sres. Oyarzún, Carreño, Araneda, Brito y A.I. Sr. Gorziglia, con disidencia de la Sra. Araneda y prevención del Sr. Brito); "Ernesto Deller Sandoval Muñoz con Contralora Regional de Aysén”, Rol 4462-09, de 4.08.2009 (Ministros Sres. Oyarzún, Carreño, Pierry, Araneda y A.I. Sr. Matriz, con disidencia de la Sra. Araneda); "Comercializadora Rodrigo Gómez Limitada con Instituto de Salud Pública", Rol 5439-09, de 10.09.2009 (Ministros Sres. Oyarzún, Carreño, Pierry, Araneda y Brito, con disidencia de la Sra. Araneda y prevención del Sr. Brito).

${ }^{8}$ El artículo único de la Ley No 18.971 (10.03.1.990) reza, en su inciso 10: "Cualquier persona podrá denunciar las infracciones al artículo 19 № 21 de la Constitución Política de la República”. 
tadas sobre el punto..." (considerando $6^{\circ}$ ), para en seguida sugerir la conveniencia de recurrir a otros elementos de interpretación "más allá del elemento gramatical", como el lógico-histórico y el sistemático, siguiendo en lo pertinente lo dispuesto en el párrafo $4^{\circ}$ del Título Preliminar del Código Civil (considerando 6º).

\section{Historia FIDEDIGNA DE LA LEY}

A fin de explicar el sentido del artículo único de la Ley No 18.971, la sentencia que comentamos recurre como primer arbitrio a la historia fidedigna de su establecimiento. Resalta al respecto que la ley en cuestión tuvo su origen en un proyecto de ley remitido por el Presidente de la República a la Junta de Gobierno -órgano legislativo de la época- con fecha 7 de septiembre de 1989, bajo el rótulo "Regula la actividad y participación productiva del Estado y sus organismos", en cuyo Mensaje se desglosan los objetivos esenciales de la iniciativa.

Hace presente que ese proyecto consultaba la existencia de "un recurso jurisdiccional para hacer efectiva la garantía constitucional de la libertad económica" (considerando $7^{\circ}$ ) frente al Estado empresario cuando éste "transgrediendo un principio de la esencia del Orden Público Económico, como lo es el de la subsidiariedad, interviene en el campo económico no acatando las limitaciones contempladas en el antes citado artículo 19 No 21 inciso $2^{\circ}$ de la Carta Fundamental, ya sea por desarrollar esa actividad sin autorización de una ley de quórum calificado o sin sujetarse a la legislación común aplicable a los particulares" (considerando $8^{\circ}$ ). Agrega que de los seis artículos que contenía el proyecto original, sólo dos de ellos se tradujeron en leyes, ambas publicadas en el Diario Oficial de 10 de marzo de 1990: el artículo $5^{\circ}$-que pasó a constituir la Ley No 18.695-, donde se estableció la obligación del Estado de vender, en el plazo de un año, los derechos que tuviere en sociedades respecto de materias ajenas al objeto para el cual se encontrara autorizado a participar o que excedieren la autorización legal respectiva.

El otro artículo del proyecto que alcanzó consagración normativa -continúa el considerando $9^{\circ}-$ fue el numeral $6^{\circ}$, trascrito, con ligeras modificaciones, en el artículo único de la Ley No 18.971. De allí extraen los sentenciadores la conclusión en orden a que el mecanismo de tutela jurisdiccional plasmado en esta norma, no pudo sino estar orientado hacia la defensa del derecho a la libertad económica, en cuanto ésta pudiere verse afectada por la actividad del Estado, llevada a cabo con infracción de lo dispuesto en el artículo 19, No 21 inciso 2o de la Carta Política (considerando $10^{\circ}$ )

Dos poderosas razones se oponen a la aceptación de este corolario. La primera es de texto: el inciso inicial del artículo único de la ley autoriza denunciar "las infracciones al artículo 19 No 21 de la Constitución...", sin distinguir entre los dos 
párrafos que comprende el precepto constitucional. Luego, "ubi lex non distinguit nec non distinguere debemos", según reza el viejo adagio, consustancial al método exegético, que es el consagrado en el artículo 19.1 del Código Civil.

Útil es recordar que el Código de Bello sólo franquea el recurso a la intención o espíritu del legislador "para interpretar una expresión obscura de la ley", cuyo no es ciertamente el caso, atendida la generalidad de la norma que interesa.

Por otra parte, el recurso a la "ratio legis" como elemento interpretativo sólo es lícito si el texto de la ley no coincide manifiestamente con la voluntad del legislador. Para decirlo en palabras del Código, es menester que la intención o espíritu de la norma, contrarios a su tenor literal, se encuentren "claramente manifestados en ella misma, o en la historia fidedigna de su establecimiento", que en seguida abordaremos.

Desde luego, pertinente es puntualizar que la historia de la ley no aporta indicios inequívocos en torno a la intención del legislador, en la forma que lo postula el intérprete judicial ${ }^{\circ}$. Como se encarga de precisarlo la Comisión Conjunta que propuso el desglose del proyecto ${ }^{10}$, la regulación general de la actividad empresarial del Estado a través de la normativa global propuesta mereció objeciones de constitucionalidad a la Secretaría de Legislación -organismo técnico de la Junta de Gobierno-y a las Comisiones Legislativas, por cuanto configuraría una suerte de orden público económico paralelo y en eventual contradicción con el de la Carta Fundamental. ${ }^{11}$

Si bien algunos informes y oficios, durante la discusión en el seno de los órganos del sistema legislativo diseñado en el gobierno militar, se orientan a subrayar la importancia de la acción jurisdiccional que se crea, para la defensa de los particulares frente a los excesos del Estado-empresario, es lo cierto que no hay antecedentes que permitan afirmar que el propósito del legislador haya sido excluir de su ámbito de cobertura los ilícitos cometidos por particulares en el desarrollo de sus actividades económicas.

Ilustrativo, en esta perspectiva, resulta el acta con que la Junta de Gobierno aprobó los dos proyectos cristalizados en las Leyes 18.971 y 18.695 citadas, donde, refiriéndose en particular al recurso plasmado en la primera, se señala simplemente: "Su texto contempla la creación de un recurso especial para garantizar los derechos de los particulares frente a las infracciones que pudieran cometerse a la norma

\footnotetext{
${ }^{9}$ Tan es así que el voto disidente de la Sra. Araneda relata antecedentes de historia del establecimiento de la norma constitucional de libre iniciativa o de libertad de empresa, que son expresivos de su sentido amplio, ratificado por la cita doctrinaria del ex -comisionado Evans (consids. $4^{\circ}$ y $5^{\circ}$ ).

${ }^{10}$ Informe No 6.583 , de $1^{\circ} .03 .1990$, de la Comisión Conjunta.

${ }^{11}$ Of. No 180-1 del Presidente de la 2a Comisión Legislativa a la Comisión Conjunta, de 13.11.1989.
} 
del No 21 del artículo 19 de la Constitución y su conocimiento y fallo quedará entregado a la Corte de Apelaciones respectiva"12.

Este y no otro era el momento para emitir una declaración oficial sobre el alcance restrictivo del precepto, si tal hubiere sido el propósito de los legisladores. Pero éstos se limitaron a mencionar la regla del artículo 19, en su numeral 21, sin acotar su sentido, lo que ilustra fehacientemente su designio de no distinguir acerca de las dos situaciones allí contempladas y, por consiguiente, de cautelar por la vía del recurso especial ambos incisos.

\section{EL ELEMENTO DE INTERPRETACIÓN SISTEMÁTICA}

Además de la historia de la ley, nuestro intérprete nos propone iluminar el pasaje, en su concepto oscuro, de la ley que crea el recurso de amparo económico, a través de un paralelo con el recurso de protección que, por remisión expresa del inciso $1^{\circ}$ del artículo 20 de la CPR., también es llamado a tutelar la misma garantía del artículo 19 No 21 de su texto.

El primer argumento dirigido a descartar el amparo económico "como instrumento idóneo para dispensar protección al derecho a desarrollar una actividad económica lícita contemplado en el artículo 19 No 21 inciso $1^{\circ}$ de la Carta Fundamental" (considerando $12^{\circ}$ ), se centra "en la imposibilidad de estimar como criterio racional que una persona directamente afectada por la vulneración de dicha garantía constitucional disponga -conforme a lo establecido en el Auto Acordado de esta Corte que regula su tramitación y fallo- de treinta días para deducir el recurso de protección, en tanto que un tercero sin interés alguno en la materia, según lo prescribe la Ley No 18.971, cuente para ello con un plazo de seis meses" (mismo considerando).

La reflexión, por cierto, es "de lege ferenda": el enunciado no le parece armónico al intérprete judicial, en la medida que el sujeto activo de una y otra acción -la constitucional de protección y la legal de amparo económico- cuentan con plazos distintos para su respectiva interposición, apreciándose como desproporcionado que, en el primer supuesto, el término para el directamente afectado por la trasgresión sea de 30 días, elevándose a seis meses en el caso de la acción de amparo económico, para cuya denuncia se concede acción popular.

Pero el presupuesto "de lege data" es otro: tanto el constituyente como el legislador orgánico constitucional dispensan auxilio jurisdiccional a los afectados por infracciones a la garantía constitucional del artículo 19, No 21 de la Carta Fundamental, sin acotar o restringir su ámbito. Obvio resulta que las mismas consideraciones sistemáticas que llevan a desconocer la procedencia de la acción de

${ }^{12}$ Boletín No 1.141-03. 
amparo económico respecto de las infracciones al principio de libertad económica, serían valederas para entenderlo improcedente en lo relativo a la vulneración de la regla que enmarca la actividad del Estado-empresario, en el inciso $2^{\circ}$ del ordinal $21^{\circ}$ en análisis, lo que se traduciría en dejar sin aplicación este instituto procesal.

En definitiva, pues, las incongruencias lógicas del sistema jurisdiccional concebido para la tutela del derecho económico reseñado, no autorizan para arribar a la conclusión forzada a que conduce este razonamiento.

Recordemos, en este punto, que la doctrina más representativa coincide con esta interpretación amplia. EVANS DE LA CUADRA, cuya autoridad en la materia se ve reforzada por su condición de ex miembro de la CENC., nos dice que "la referencia al No 21 del artículo 19 debe entenderse a todo el contenido, porque la ley no distinguió, respecto de los dos incisos que contiene, es decir, tanto al derecho a desarrollar actividades económicas como a la limitación impuesta al Estado para desarrollar actividades empresariales consistentes en la autorización, otorgada al efecto, por ley aprobada con quórum calificado". Para en seguida agregar: "Entender el precepto de la Ley No 18.971 en otra forma es restringirlo más allá de lo que su texto permite y hacer distinciones no contempladas expresamente, lo que vulnera principios básicos de hermenéutica" ${ }^{13}$.

Aunque retórico paralógico -como se le ha criticado- el argumento "magister dixit" nos interpreta en esta oportunidad cabalmente.

\section{LA ESPECIFICIDAD DE LA INTERPRETACIÓN CONSTITUCIONAL: \\ UNA LLAMATIVA OMISIÓN}

Como ocurre frecuente y paradojalmente con las resoluciones de la Sala Constitucional de la Corte Suprema, el razonamiento utilizado en esta oportunidad está también marcado por un sesgo civilista: se busca dilucidar el problema a través de la metodología interpretativa plasmada en el Título Preliminar del Código Civil, en lugar de reconocer que aquél se enmarca en la temática constitucional, sujeta a sus propias reglas, que le otorgan una especificidad propia, como lo proclama reiteradamente la jurisprudencia del Tribunal Constitucional ${ }^{14}$.

\footnotetext{
${ }^{13}$ Evans de la CuAdra, Enrique: "Los derechos constitucionales", T. III, $2^{a}$ ed. actualizada, EJCH., Stgo., 1999, p. 149.

${ }^{14}$ Subraya ZAPATA que "[E]1 TCCh ha reivindicado expresamente la existencia de criterios de interpretación dimanados directamente de la Carta Fundamental, los que deben ser seguidos aun cuando aparecieren en conflicto con las reglas del Código Civil. Así, en "Restricción Vehicular", el TCCh señaló: "Que una interpretación literal o basada en el principio de la especialidad o en el aforismo jurídico de que donde la ley no distingue no le es lícito al intérprete hacerlo, establecidas o reconocidas por el Código Civil, para la interpretación de las leyes, no reciben aplicación en el presente caso, atendida la naturaleza especial del problema
} 
Según observa NogUeIRA, la interpretación constitucional puede sistematizarse a través de "postulados hermenéuticos", que "funcionan como ideas reguladoras que apuntan en la dirección que debe ser seguida por el intérprete de la Carta Fundamental"15.

Entre estos postulados destaca el de unidad de la Constitución, que caracteriza la Constitución como un todo orgánico, el sentido de cuyas normas "debe ser determinado de manera tal que exista entre ellas la debida correspondencia y armonía, excluyéndose cualquiera interpretación que conduzca a anular o a privar de eficacia algún precepto de ella"16.

En el mismo sentido discurre el principio o postulado del efecto útil, conforme al cual "cuando una disposición es susceptible de dos sentidos, es preferible entenderla en aquel que le permita tener algún efecto antes que en el sentido con el cual no podría producir ninguno" ${ }^{17}$.

Finalmente, el postulado de interpretación conforme a la Constitución-también denominado de "presunción de constitucionalidad"- aplicable al ámbito de las normas infraconstitucionales, obliga al aplicador de estas últimas a preferir, de entre varias opciones interpretativas posibles, aquella que mejor se concilie con la Carta Fundamental. También ha sido recogido en variadas sentencias del TC., como v. gr. en "Pueblos indígenas" (Rol 309, de 4.08.2000), considerando 20 del cap. I; "Nuevo estatuto de capacitación y empleo" (Rol 257, de 2.09.1997), consid. 12o; "Fomento Forestal" (Rol 271, de 31.01.1991), considerando 7o; "Ley orgánica constitucional del Ministerio Público" (Rol 293, de 28.09.1999), consid. 24\%; "Racionalización del sector Hacienda" (Rol 297, de 2.11.1999), consid. $13^{\circ}$ y "Normas adecuatorias del sistema legal chileno a la reforma procesal penal" (Rol 349, de 30.04.2002), considerando 34.

Es fácil concluir que la Corte Suprema no incursiona, en el veredicto comentado, por esta vertiente hermenéutica específica. Tampoco suele recorrerla, en general, en su jurisprudencia asociada a temas constitucionales. De allí que la

que se analiza y del texto que se interpreta..." (Zapata LARRAín, Patricio: "Justicia Constitucional. Teoría y Práctica en el Derecho Chileno y Comparado”, $1^{a}$ ed., EJCH., Stgo, 2008, p. 172).

La referencia es al fallo Rol 325 del TCCh, de 26.06.2001, consid. 13.

${ }^{15}$ Nogueira Alcalé, Humberto: "Enfoques sobre interpretación constitucional y jurisdicción constitucional", en: "Temas actuales de Derecho Constitucional. Libro Homenaje al Profesor Mario Verdugo Marinkovic", EJCH., Stgo., 2009, p. 157.

${ }^{16}$ STC. Rol 33, de 24.09.1985, consid. 19º, citada por Nogueira en op. cit., p. 160, con referencia a varios otros pronunciamientos del mismo TC., en idéntica orientación. Véase, además, Valenzuela SomarRIVA, Eugenio: "Criterios de hermenéutica constitucional aplicados por el Tribunal Constitucional", Cuadernos Tribunal Constitucional No 31, 2006, pp. 24 y ss.

${ }^{17}$ LuCHaire, citado por Nogueira en op. cit., p. 162. 
insuficiencia denunciada devenga tan significativa, en la medida que, de haber seguido nuestro intérprete judicial los derroteros del método constitucional, no habría dejado sin aplicación el inciso $2^{\circ}$ del tantas veces mentado numeral 21 del artículo 19 de la Carta Política, con flagrante desconocimiento de los postulados hermenéuticos específicos antes enunciados.

\section{6. ¿LA ACCIÓN DE AMPARO ECONÓMICO}

TIENE EFECTIVAMENTE UN SENTIDO PURAMENTE DECLARATIVO?

Según consta de su texto -consigna el considerando $12^{\circ}$ de nuestra sentencia- "la Ley No 18.971 únicamente permite al órgano jurisdiccional encargado de conocer las denuncias a que ella se refiere declarar en su fallo -si existe mérito para ello- la existencia de la infracción a la norma constitucional". Ello sería consecuencia de no haberse entregado al órgano jurisdiccional "la facultad de adoptar providencias cautelares prontas e inmediatas para brindar resguardo al afectado, como sí se establecen en el artículo 20 de la Constitución Política tratándose del recurso de protección" (mismo considerando).

En apoyo de esta deducción, se remonta el jurisdicente a la historia de la Ley No 18.971 , recordando que el inciso $5^{\circ}$ del artículo $6^{\circ}$ del proyecto que le sirvió de antecedente, autorizaba expresamente a la Corte para adoptar "las providencias que juzgue necesarias para restablecer el imperio del derecho e impedir que se consumen o mantengan las infracciones denunciadas", disposición que no se incorporó en definitiva al texto aprobado de la ley, lo que sería demostrativo del ánimo del legislador de no otorgar al tribunal competente estas atribuciones.

Esta propuesta explicativa tuvo su origen, hacia el año 2001, en una prevención del Ministro Sr. Ricardo Gálvez recaída en el RAE. "Productos del Mar Ventisqueros S.A. con Gobernador Provincial de Palena" ${ }^{\text {". }}$. Con el correr del tiempo, la prevención del señalado Ministro se transformó en doctrina de la Corte, a partir del segundo semestre de 2001, cuyo punto de partida es la sentencia "Sociedad Constructora Santa María del Campo Ltda. con Director del Servicio de Vivienda y Urbanismo de la Región de Coquimbo y Contraloría Regional de Coquimbo"”, donde se sostiene, en lo pertinente:

\footnotetext{
${ }^{18}$ SCS. de 28.06.2001 (Ministros Sres. R. Gálvez B., O. Álvarez H., D. Yurac S. y Abogados Integrantes Sres. M. Daniel A. y F. Geldres A.), aprobatoria de la sentencia consultada, de 28.06.2001, de la CA. de Pto. Montt, que acogió el recurso interpuesto, ordenando al recurrido "tomar todos los resguardos para que los derechos garantidos en la Constitución no se afecten en su esencia".

19 SCS. Rol 3796-01, de 29.10.2001 (Ministros Sres. R. Gálvez B., H. Espejo Z., J. Medina C. y Abogados Integrantes Sres. F. Castro A. y J. Infante P. (redactor) confirmatoria de SCA. de La Serena.

La prevención -transformada hoy en doctrina de la $3^{a}$ Sala de la Corte Suprema- provocó en su momento el "estupor" del Prof. Soto, quien anota que lo propio de las acciones de amparo "es restablecer el imperio del
} 
"50) Que sólo si se comprueba la infracción, el fallo deberá así declararlo, sin que el tribunal quede en situación de adoptar alguna medida al respecto, puesto que la aludida ley no lo autoriza y conforme a lo dispuesto en el artículo 70 de la Constitución Política de la República, ninguna magistratura puede atribuirse otra autoridad o derechos que los que expresamente se le hayan conferido, siendo nulos los actos que asi se realicen".

La postura aquí graficada, pese a su permanencia en el tiempo de casi una década, representa -como tuvimos oportunidad de sustentarlo en algún anterior comentario jurisprudencial ${ }^{20}$ - una involución respecto de una sólida y garantista tendencia mantenida con antelación por la Corte Suprema, a partir de la definición de la acción que interesa como una acción jurisdiccional de carácter conservadora" (sic) que, como tal, autoriza a la jurisdicción para adoptar medidas o providencias conducentes al restablecimiento del derecho constitucional conculcado. Así, además de "declarar" la existencia de la infracción, se establecía:

- La anulación directa -bajo la fórmula, preferida normalmente por los Tribunales Superiores, de "dejar sin efecto" actos administrativos- correspondiendo además al ente administrativo responsable de la ilegalidad "adoptar las medidas conducentes al inmediato restablecimiento de las actividades propias"... (del actor afectado) $)^{21}$;

- La orden impartida a la Administración de anular ciertos oficios y de abstenerse de aplicar un decreto supremo vigente ${ }^{22}$;

derecho y otorgar amparo al afectado, lo que significa que el tribunal "declara" contrario a derecho el acto, hecho u omisión denunciado como agraviante de un derecho fundamental por el recurrente y luego adopta una "medida de amparo" para resguardo de ese derecho lesionado, medida que aparta o elimina dicho acto, hecho u omisión antijurídico". La omisión de adoptar medidas -continúa el articulista- "sería una vulgar farsa y un engaño o burla para el afectado", toda vez que en todos los amparos -cita dentro del género los de habeas corpus, protección, amparo económico, de aguas, de minas, de datos, de publicidad de la Ley No 18.575, art. 14- hoy derogado - de posesión, etc.- lo fundamental es la "medida" que ampara", dispuesta por el tribunal precisamente en ejercicio de sus atribuciones "conservadoras", dirigidas al ejercicio efectivo de los derechos de las personas y "la sujeción de los órganos públicos a la Constitución, con pleno respeto de esos derechos" (Eduardo Soto Kloss, en RDJ. 98-2, 2001, II-5a, nota en pp. 146-147).

${ }^{20}$ Domingo Hernández Emparanza, "Comentario Recurso de Amparo Económico: Corte de Apelaciones de Santiago, Rol No 47-2006", en: "Gaceta Jurídica" No 309 (marzo 2006), pp. 41-46, rectificado en "Gaceta Jurídica" No 310, p. 41.

${ }^{21}$ S.C.S. "Empresa Metropolitana de Tratamiento y Disposición de Basuras Ltda. con Alcalde I. Municipalidad de San Ramón”, Rol No 4482, de 8.01.1998 (Ministros Sres. O. Faúndez V., A. Toro L., E. Tapia W. y Abogados Integrantes Sres. A. Rencoret S. y J. Bernales P.), confirmatoria de la S.C.A.S. de 17.12.1997, publicada en G.J. No 211, pp. 32-39.

22 S.C.S. "Marga-Publicidad Ltda. con Dirección de Vialidad de la Región Metropolitana”, Rol No 3982, de 9.12.1999 (Ministros Sres. R. Gálvez B., O. Álvarez H., D. Yurac S. y Abogados Integrantes Sres. M. Daniel A. y J. Fernández R.), publicada en G. J. No 234, pp. 29-34. Puede advertirse que ésta -la tesitura clásica de la C.S.- era también la de la actual $3^{\text {a }}$ Sala de ese Tribunal Superior, hasta la vuelta de timón, producida a fines de 2001. 
- La exigencia a una empresa pública del Estado de dar cumplimiento, en un término perentorio de tercero día, a obligaciones contraidas en un contrato de mandato suscrito con la sociedad demandante ${ }^{23}$;

- La orden de cesar de inmediato en la práctica de una actividad empresarial de naturaleza periodística, destinada a ser realizada por una sociedad anónima estatal, en colaboración con otras sociedades comerciales privadas ${ }^{24}$.

No se requiere, entonces, de un particular esfuerzo, especulativo para arribar a la conclusión de que las citadas facultades conservadoras forman parte integrante de la jurisdicción reconocida a los tribunales por el artículo 73 de la Constitución Política de la República, como por lo demás lo explicita el mencionado artículo $3^{\circ}$ del Código Orgánico de Tribunales y que, por su intermedio, el Poder Judicial queda siempre facultado, sin necesidad de una declaración expresa y formal del legislador, para adoptar las providencias dirigidas a prestar efectiva salvaguardia a los derechos fundamentales, sin que, con esta actitud, tan inherente a la naturaleza de los "amparos" cautelares, se conculque, en modo alguno, el principio de legalidad. Por lo demás, la garantía del artículo 19, No 21, en cuanto integrada al capítulo de los derechos constitucionales, análoga éstos a los "esenciales" propios de la naturaleza humana, para cuya defensa el Derecho Internacional de los Derechos Humanos obliga a proveer un recurso "sencillo y rápido o cualquier otro recurso efectivo ante los jueces o tribunales competentes, que la ampare (a toda persona) contra actos que violen sus derechos fundamentales". En esta dimensión, la hermenéutica debe privilegiar el principio "favor libertatis", que obliga a preferir la interpretación que mejor proteja los derechos de las personas, especialmente en presencia de presuntos vacíos normativos, como el que invoca la tesis aceptada por la C.S.

Siendo ostensible que la mera declaración de existencia de una infracción a la regla sobre garantía del orden público económico, aludida en la Ley No 18.971, forzará al denunciante favorecido a iniciar un nuevo juicio para obtener la anulación del acto antijurídico o la imposición de la conducta positiva o negativa que el fallo de mera certeza no incluyó, el RAE devendrá ineludiblemente ineficaz, en términos que convalidan, necesariamente, la solución alternativa que se propicia, como la única que armoniza con la visión del Estado como promotor de los derechos fundamentales -en el inciso $2^{\circ}$ del artículo $5^{\circ}$ de la Carta- y de los tribunales de justicia, como auténticos garantes de su real vigencia.

\footnotetext{
${ }^{23}$ S.C.S. "Comercial Menichetti S.A.I. con Banco del Estado", Rol No 28.03.1995, (Ministros Sres. O. Faúndez V., L. Béraud P., A. Toro L., G. Valenzuela E. y Abogado Integrante Sr. M. Daniel A.), confirmatoria de la S.C.A.S. de 26.01.1995, consid. 5º, publicadas en G.J. No 177, pp. 20-25.

${ }^{24}$ S.C.S. "Asociación Nacional de la Prensa A.G. con Empresa de Transporte de Pasajeros Metro S.A.”, Rol No 248-00. de 31.01.00 (Ministros Sres. O. Faúndez V., R. Gálvez B., O. Álvarez H., D. Yurac S. (redactor) y H. Espejo Z.), publicada en G.J. No 235, pp. 37-52
} 
Es precisamente la vertiente hermenéutica clásica y no la vigente, la que mejor se concilia con nuestra más selecta tradición jurisprudencial. Ésta encuentra uno de sus puntos más altos en el proverbial precedente "Juez de Letras de Melipilla con Presidente de la República", donde se nos recordaba que "por sobre todos los razonamientos de orden meramente legal", existe en juego siempre un problema "de la mayor trascendencia para el normal funcionamiento del orden jurídico dentro del Estado de Derecho, cual es la garantía del ciudadano frente al poder público”, la que en gran medida reposa en "una de las funciones que el artículo $3^{\circ}$ del código institucional confía a los Tribunales de Justicia: facultades conservadoras para proteger el ejercicio de los derechos que consagra la Carta Fundamental..."2s.

No se requiere, entonces, de un particular esfuerzo especulativo para arribar a la conclusión de que las citadas facultades conservadoras forman parte integrante de la jurisdicción reconocida a los tribunales por el artículo 73 de la CPR., como por lo demás lo explicita el mencionado artículo $3^{\circ}$ del Código Orgánico de Tribunales y que, por su intermedio, el Poder Judicial queda siempre facultado, sin necesidad de una declaración expresa y formal del legislador, para adoptar las providencias dirigidas a prestar efectiva salvaguardia a los derechos fundamentales, sin que, con esta actitud, tan inherente a la naturaleza de los "amparos" cautelares se conculque, en modo alguno, el principio de legalidad.

\section{LA INTERPRETACIÓN CONFORME AL DERECHO INTERNACIONAL}

Dada la gravedad que entraña para un Estado, en el ámbito internacional, la declaración de inconstitucionalidad de las normas de un tratado por un órgano jurisdiccional interno, se ha entendido por el Tribunal Constitucional que es obligatorio para el intérprete "hacer todos los esfuerzos dentro de lo permitido por la Ley Suprema, para encontrar una interpretación conciliatoria entre las normas de un tratado y los preceptos de la Constitución"26.

Este principio, referido por NogUEIRA como "de interpretación conforme al derecho internacional" ${ }^{27}$, hace preceptivo el análisis de todos los temas asociados a las garantías de derechos de las personas, en el marco de esta última rama del derecho.

Pertinente es remarcar, en esa dimensión, que la categoría de los "derechos económicos", reconocidos como tales tanto en el PIDESC. (art. 3º), como en la

\footnotetext{
${ }^{25}$ SCS. "Juez de Letras de Melipilla con Presidente de la República", consid. 9º, en: RDJ. 1967, cit. en "Los tribunales contencioso-administrativos", Junta de Gobierno de la República de Chile, Stgo., 1982, pp. 223-239.

${ }^{26}$ STC. Rol 309, de 4.08.2000, consid. 30.

${ }^{27}$ Ob. y aut. cit., pp. 173-174.
} 
CADH. (art. 26), cuentan con un mecanismo reforzado de protección jurisdiccional, particularmente en el último de estos instrumentos internacionales. Es así como la Convención Americana reconoce a toda persona el "derecho a un recurso sencillo y rápido a cualquier otro recurso efectivo ante los jueces o tribunales competentes, que la ampare contra actos que violen sus derechos fundamentales reconocidos por la Constitución, la ley o la presente Convención, aun cuando tal violación sea cometida por personas que actúen en ejercicio de sus funciones oficiales" (art. 25.1).

Los Estados Partes se comprometieron, además, a "garantizar que la autoridad competente prevista por el sistema legal del Estado decidirá sobre los derechos de toda persona que interponga tal recurso" (art. 25.2.a) y a "garantizar el cumplimiento, por las autoridades competentes, de toda decisión en que se haya estimado procedente el recurso" (art. 25.2.c). Adicionalmente, la Convención prohíbe interpretar ninguna de sus disposiciones en el sentido de "limitar el goce y ejercicio de cualquier derecho o libertad que pueda estar reconocido de acuerdo con las leyes de cualquiera de los Estados Partes o de acuerdo con otra convención en que sea parte uno de dichos Estados" (art. 29.b).

Este entorno normativo impone una lectura radicalmente distinta acerca del alcance de la acción de amparo económico, respecto de la ofrecida por nuestro máximo tribunal. Ofrece un punto de vista centrado en la existencia de un recurso realmente "efectivo" en la defensa de los derechos económicos de los ciudadanos, para lo cual se enfatiza el deber de la jurisdicción de "decidir" sobre el derecho de los recurrentes y "garantizar" el cumplimiento de la "decisión" recaída en dicho recurso.

Si a lo anterior se agrega que le está vedado a los países suscriptores del tratado limitar el ejercicio de los derechos reconocidos en sus leyes domésticas, la conclusión que más se acomoda con el derecho internacional es necesariamente aquélla amplia o extensiva que mejor proteja los derechos de las personas, en presencia de presuntos vacíos normativos, como los que denuncia la tesis aceptada por la Corte Suprema: ésta es la que, proclamando la naturaleza cautelar del amparo económico, reconoce a los tribunales competentes el derecho a conocer y fallar la situación denunciada, con plenas facultades para adoptar todas las medidas que el caso amerite, las que son inherentes a sus facultades conservadoras, ínsitas en la jurisdicción, amén de avenirse plenamente con el criterio de interpretación conforme al derecho internacional, que hemos reseñado ${ }^{28}$.

\footnotetext{
${ }^{28}$ Ésta parece ser la visión del Ministro Sr. Brito, quien califica la acción como de "índole cautelar" (considerando $2^{\circ}$ de su críptica prevención).
} 


\section{ANEXO}

Sentencia “González Illanes, Sergio Luis

con I. Municipalidad de Santiago"

C.S. Rol No 501-2009 (1º4.2009)

Santiago, uno de abril de dos mil nueve.

VISTOS:

De la sentencia en consulta se reproducen sus fundamentos primero y segundo.

Se la elimina en lo restante.

Y SE TIENE EN SU LUGAR PRESENTE:

Primero: Que según quedó expresado en los considerandos que se han reproducido de la sentencia consultada, en estos autos se ha ejercido por don Sergio Luis González Illanes la llamada acción de amparo económico prevista en el artículo único de la Ley $N^{\circ}$ 18.971, en resguardo de su derecho a desarrollar una actividad económica lícita garantizado en el artículo 19 No 21 inciso $1^{\circ}$ de la Constitución Política de la República, el que, según señala, se vulneró por el Decreto Alcaldicio No 1524 de 29 de agosto de 2008 dictado por el Alcalde de la Municipalidad de Santiago, mediante el cual se dispuso la clausura de un taller mecánico de su propiedad; e impetró, en lo conclusivo, que se dejara sin efecto dicha decisión administrativa y se ordenara a la autoridad municipal que se le conceda patente para amparar el funcionamiento de ese local;

Segundo: Que en función de las consideraciones que más adelante se desarrollarán, resulta conveniente transcribir lo preceptuado en el artículo 19 No 21 de la Carta Fundamental, que asegura a todas las personas: El derecho a desarrollar cualquiera actividad económica que no sea contraria a la moral, al orden público o a la seguridad nacional, respetando las normas legales que la regulan (inciso $1^{\circ}$ ).

El Estado y sus organismos podrán desarrollar actividades empresariales o participar en ellas sólo si una ley de quórum calificado los autoriza. En tal caso, esas actividades estarán sometidas a la legislación común, sin perjuicio de las excepciones que por motivos calificados establezca la ley, la que deberá ser, asimismo, de quórum calificado (inciso $2^{\circ}$ );

Tercero: Que la cuestión que se ha planteado en estos antecedentes ofrece una oportunidad propicia para reexaminar el tema concerniente al sentido y alcance que corresponde reconocerle al instituto jurisdiccional previsto en la mencionada Ley $N^{o}$ 18.971: si constituye, como en general se ha venido sosteniendo en estos últimos años, un instrumento idóneo para conocer por su intermedio de las denuncias por infracciones a la garantía contemplada en ambos incisos del aludido artículo 19 No 21 de la Constitución Política; o si, por el contrario, según también se ha propugnado, su uso queda constreñido como medio destinado a entender de las vulneraciones a la 
garantía de la libertad económica provenientes de la actividad empresarial del Estado a que se refiere el inciso $2^{\circ}$ de ese precepto constitucional;

Cuarto: Que la Ley No 18.971 consta de un artículo único, en que se establece: Cualquier persona podrá denunciar las infracciones al artículo $19 N^{\circ} 21$ de la Constitución Política de la República.

El actor no necesitará tener interés actual en los hechos denunciados.

La acción podrá intentarse dentro de seis meses contados desde que se hubiere producido la infracción, sin más formalidad ni procedimiento que el establecido para el recurso de amparo ante la Corte de Apelaciones respectiva, la que conocerá de ella en primera instancia.

Deducida la acción, el tribunal deberá investigar la infracción denunciada y dar curso progresivo a los autos hasta el fallo respectivo.

Contra la sentencia definitiva, procederá el recurso de apelación, que deberá interponerse en el plazo de diez días para ante la Corte Suprema y que, en caso de no serlo, deberá ser consultada. Este Tribunal conocerá del negocio en una de sus Salas.

Si la sentencia estableciere fundadamente que la denuncia carece de toda base, el actor será responsable de los perjuicios que hubiere causado;

Quinto: Que la proposición enunciada en el basamento tercero hace necesario inquirir acerca del alcance que cabe asignar a lo preceptuado en la norma que se viene de transcribir, la cual, si bien denota claridad en su tenor literal, no ocurre lo mismo con su sentido, que resulta ambiguo en cuanto a la finalidad que tuvo en vista el legislador al establecerla; situación que ha dado pábulo a la divergencia de opiniones sustentadas sobre el punto a que se hizo referencia precedentemente;

Sexto: Que en pos de una conclusión correcta en torno a esta materia, obligadamente ha de acudirse a otros principios de interpretación más allá del elemento gramatical, entre aquellos comprendidos en las reglas de hermenéutica que contempla el párrafo $4^{\circ}$ del Titulo Preliminar del Código Civil, como el lógico-histórico, que busca descubrir la intención o espiritu de la ley en la historia fidedigna de su establecimiento (artículo 19 inciso $2^{\circ}$ ) y el elemento sistemático, por el que se pretende alcanzar el mismo objetivo en la unidad o conexión que las diversas instituciones guardan en el conjunto del ordenamiento jurídico (artículo 22);

Séptimo: Que el enfoque histórico de la norma en estudio hace indispensable considerar el proyecto de ley remitido por el Presidente de la República a la Junta de Gobierno órgano legislativo de la época -con fecha 7 de septiembre de 1989-, bajo el rótulo Regula la Actividad y Participación Productiva del Estado y sus Organismos.

En el Mensaje con que se acompañó dicho proyecto se enunciaban como postulados esenciales del mismo los que propiciaban la iniciativa particular en la actividad económica y la excepcionalidad de la intervención en ella por parte del Estado empresario, consignándose en semejante contexto tres clases de normas: unas, de carácter 
general, aplicables a toda legislación relativa a la actividad empresarial del Estado o en que a éste le quepa participación; otras, en que se fija el ámbito dentro del cual el Estado desarrollará actividades de ese tipo; y una, en particular, donde se establece un recurso jurisdiccional para hacer efectiva la garantía constitucional de la libertad económica;

Octavo: Que la frase con que finaliza el considerando anterior permite inferir que con el recurso jurisdiccional a que ella alude se propende a amparar la garantía constitucional de la libertad económica frente al Estado empresario, cuando éste, transgrediendo un principio de la esencia del Orden Público Económico Nacional, como lo es el de la subsidiaridad, interviene en el campo económico no acatando las limitaciones contempladas en el antes citado artículo $19 N^{\circ} 21$ inciso $2^{\circ}$ de la Carta Fundamental, ya sea por desarrollar esa actividad sin autorización de una ley de quórum calificado o sin sujetarse a la legislación común aplicable en dicho ámbito a los particulares;

Noveno: Que siguiendo la esbozada línea de razonamiento, cabe apuntar que de los seis artículos de que se componía el proyecto en comento, sólo dos de ellos se concretaron en leyes, ambas publicadas en el Diario Oficial del 10 de marzo de 1990. Uno fue el artículo 50, que pasó a constituir la Ley $N^{\circ} 18.965$, donde se establece la obligación del Estado en orden a vender en el plazo de un año los derechos que tuviere en sociedades respecto de materias ajenas al objeto para el cual se encontrara autorizado a participar o que excedieron la autorización legal respectiva.

El otro artículo del proyecto que alcanzó consagración normativa y que interesa al presente análisis, fue el número 6, que se tradujo, con algunas modificación de menor entidad, en la Ley $N^{o} 18.971$ cuyo texto se transcribió anteriormente;

Décimo: Que las reflexiones que se vienen de desarrollar, especialmente las que se contienen en el considerando octavo, permiten inferir que el legislador de la Ley $N^{o} 18.971$ instituyó un mecanismo de tutela jurisdiccional destinado a amparar a los particulares en su derecho a la libertad económica cuando ella resulte afectada por la actividad del Estado llevada a efecto con infracción a las regulaciones que sobre la materia se establecen en el artículo $19 N^{\circ} 21$ inciso $2^{\circ}$ de la Constitución Política; determinación que, de seguro, obedeció al convencimiento de quienes propiciaron el establecimiento de dicho cuerpo normativo en orden a que el recurso de protección contemplado en el artículo 20 de la misma Carta carecía de la aptitud requerida para constituir un res guardo con la eficacia suficiente respecto de la intangibilidad que debe ostentar dicha garantía esencial;

Undécimo: Que a la misma conclusión se arriba interpretando sistemáticamente la Ley $N^{o} 18.971$ y el artículo 20 de la Constitución Política de la República.

Mientras este último precepto, en efecto, establece una acción el llamado recurso de protección - a favor de quien, como consecuencia de acciones u omisiones ilegales $o$ 
arbitrarias de terceros, sufra privación, perturbación o amenaza en el legítimo ejercicio de determinados derechos o garantías esenciales ?entre las que se incluye la señalada en el artículo $19 N^{\circ} 21$ de la Carta-, el artículo único de la Ley $N^{\circ}$ 18.971, en que se regula el denominado amparo económico, prescribe que cualquiera persona puede denunciar las infracciones al recién aludido artículo $19 N^{\circ} 21$, sin que el actor necesite tener interés actual en los hechos a que se refiere la denuncia.

Crea asi la Ley No 18.971 una acción popular, que trasunta el designio del legislador en orden a amparar por su intermedio el derecho a la libertad económica no en cuanto a transgresiones a la misma que afecten en general a los individuos particulares en su interés personal, sino cuando tales vulneraciones provengan de la actividad empresarial del Estado quebrantando las normas de Orden Público Económico consagradas en el tantas veces mencionado artículo $19 N^{\circ} 21$ inciso $2^{\circ}$ de la Constitución Política.

La generación de un instrumento jurídico específico en defensa de esta garantía, sin duda, se hizo patente para el legislador-según antes se hizo notar-frente a la insuficiente eficacia del recurso de protección para asumir ese rol en diversos aspectos, tales como la explicable falta de motivación de las personas, individualmente consideradas, para deducir un recurso de protección en resguardo del derecho a la libertad económica como un derecho de carácter general, al no sentirse afectadas en un derecho subjetivo que les concierna en lo particular;

Duodécimo: Que, por otra parte, existen fundadas razones que conducen a descartar el amparo económico como instrumento idóneo para dispensar protección al derecho a desarrollar una actividad económica lícita contemplado en el articulo $19 N^{\circ} 21$ inciso $1^{\circ}$ de la Carta Fundamental.

La primera de ellas estriba en la imposibilidad de estimar como criterio racional que una persona directamente afectada por la vulneración de dicha garantía constitucional disponga-conforme a lo establecido en el Auto Acordado de esta Corte que regula su tramitación y fallo- de treinta días para deducir el recurso de protección, en tanto que un tercero sin interés actual alguno en la materia, según lo prescribe la Ley No 18.971, cuente para ello con un plazo de seis meses.

En seguida, el diseño con que el referido cuerpo legal reguló el amparo económico impide considerarlo como un remedio eficaz disponible a favor de un particular para la salvaguarda de la garantía en referencia, desde que no se entregó al órgano jurisdiccional la facultad de adoptar providencias cautelares prontas e inmediatas para brindar resguardo al afectado, como sí se establecen en el artículo 20 de la Constitución Politica tratándose del recurso de protección.

Cabe tener presente a este respecto que el proyecto anteriormente mencionado, que dio origen a la Ley $N^{\circ}$ 18.971, en el inciso $5^{\circ}$ de su artículo $6^{\circ}$ disponia: La Corte 
adoptará de inmediato las providencias que juzgue necesarias para restablecer el imperio del derecho e impedir que se consumen o mantengan las infracciones denunciadas.

Esta parte del proyecto, de clara finalidad cautelar, no se incorporó en definitiva al texto de dicha ley, que recogió sustancialmente el contenido del articulo. Esta parte del proyecto, de clara finalidad cautelar, no se incorporó en definitiva al texto de dicha ley, que recogió sustancialmente el contenido del artículo $\sigma^{\circ}$ de dicha iniciativa.

De esta manera, según consta de su texto -transcrito con anterioridad-la Ley $N^{o} 18.971$ únicamente permite al órgano jurisdiccional encargado de conocer las denuncias a que ella se refiere declarar en su fallo-si existe mérito para ello-la existencia de la infracción a la norma constitucional;

Decimotercero: Que las razones de que se ha hecho acopio a lo largo del presente fallo en torno a la proposición formulada en su considerando tercero resultan aptas para producir en estos sentenciadores el suficiente grado de convencimiento en orden a la inidoneidad del llamado recurso de amparo económico para salvaguardar la garantía fundamental reconocida en el artículo $19 N^{\circ} 21$ inciso $1^{\circ}$ de la Carta Fundamental.

Siendo ello así, la circunstancia que la persona afectada en el legitimo ejercicio del mencionado derecho pueda plantear semejante acción al permitírselo el inciso $1^{\circ}$ del artículo 20 de la Constitución Política en su parte final (en cuanto alli se dispone que la formulación del recurso de protección no obsta a invocar los demás derechos que se puedan hacer valer ante la autoridad o los tribunales correspondientes); a lo que cabe sumar el hecho que, frente a una denuncia presentada en el sentido señalado, el tribunal respectivo no podría excusarse de darle tramitación sin incurrir en vulneración a lo preceptuado en el artículo 10 inciso $2^{\circ}$ del Código Orgánico de Tribunales, no significa que, en definitiva, mediante dicha vía procesal especifica la persona afectada quede en condiciones de ver satisfecha su pretensión de cautela de la garantía en comento; amparo que sí puede proporcionarle de manera pronta, ágil y eficaz la acción - o recurso- de protección instituida en el tantas veces citado artículo 20 de la Carta Fundamental;

Decimocuarto: Que el recurso de amparo económico deducido en autos no puede, por ende, prosperar.

$Y$ de conformidad con lo dispuesto en la Ley $N^{o} 18.971$ de 1990, se revoca la sentencia consultada de nueve de diciembre de dos mil ocho, escrita a fojas 62 y siguientes, en cuanto por su resuelvo b) acogió parcialmente el recurso de amparo económico formulado por don Sergio Luis González Illanes y, en su lugar, se declara que dicho recurso queda rechazado.

Se previene que el Ministro señor Brito si bien concurre a la decisión de revocar la sentencia en alzada y negar lugar al recurso de amparo económico de estos anteceden- 
tes, no comparte los motivos octavo y siguientes, y que para integrar la mayoría tuvo unicamente en cuenta las consideraciones que siguen.

19. A su juicio, no es posible dar a la Ley $N^{o} 18.971$ un alcance restrictivo en el sentido de entender que sólo dice relación con la cautela del principio de subsidiariedad en materia económica porque su texto carece de expresiones en tal sentido; y porque si bien es cierto que este cuerpo legal deriva del Proyecto de Ley que Regula la Actividad y Participación Productiva del Estado y sus Organismos, de 7 de septiembre de 1989, y que entre las motivaciones de éste ha de reconocerse la de evitar la proliferación de empresas de propiedad estatal, no lo es menos que no llegó a dictarse un cuerpo sistemático de normas jurídicas del que pudiere concluirse tal alcance sino únicamente la que nos ocupa y que se aprecia completamente desvinculada del contexto de la legislación, $y$ de muy difícil comprensión. Tal resultado del proyecto lleva a restar valor a dicha motivación. Es útil consignar que una segunda norma del proyecto fue incorporada a otra ley con las mismas características.

$2^{a}$. Por otra parte, toda vez que en concepto del disidente la pretensión de que se trata es de indole cautelar y no declarativa puesto que ningún sentido podría tener obtener un fallo que se limite a poner de manifiesto la infracción a la garantía constitucional, atendido que el artículo 20 de la Constitución Política de la República con anterioridad a la vigencia de dicha ley hizo procedente el recurso de protección respecto de la libertad para el ejercicio de actividades económicas, no es posible sino representarse las alternativas de que este derecho dispone de dos acciones que cumplen la misma función mediante procedimientos distintos; y un segundo entendimiento en orden a que estas acciones se refieren a objetos diversos, tal como lo hace la mayoria pero circunscribiéndola al criterio de subsidiariedad.

No se advierten razones jurídicas que justifiquen la primera, y si hubiere que aceptar la duplicidad ello sería consecuencia de una inobservancia legislativa. Por el contrario, a resultas de haberse previsto para el caso del recurso de amparo económico que para ejercer esta acción no se requiere interés jurídico actual, de haberse consignado en la misma ley el amplio plazo de seis meses para dar inicio al procedimiento, y de estatuirse el trámite de consulta de la sentencia definitiva cuando no fuere apelada, ha de concluirse que el legislador de la época tuvo en consideración un objeto distinto al que conferia especial relevancia, porque si se tratase del mismo no hay razón para la duplicidad. Las formas del nuevo procedimiento que se han puesto de manifiesto inequivocamente obedecen a la intención de alcanzar para este objeto distinto una cautela más eficiente.

3a. El previniente entiende que ambas acciones cautelan el derecho a la libertad económica, y que se diferencian porque mientras la de protección es procedente respecto de alguna persona determinada, la de amparo económico ha de emplearse en relación con infracciones al referido derecho por causa de actos que la lesionen del mismo modo, 
esto es en alguno de sus múltiples aspectos, pero que además significan una vulneración a las definiciones básicas del sistema económico.

Atendidas estas y la incuestionable necesidad de disponer de medios de cautela eficientes, es que el legislador previno esta acción dotada de las ya referidas características procedimentales, incluso de la revisión no obstante la inexistencia de agravio.

4a. Que en el obrar de la recurrida no se aprecia ninguna afectación de esta clase, motivo por el cual el previniente estuvo por revocar la sentencia y negar lugar al recurso de amparo económico de estos antecedentes.

Acordada con el voto en contra de la Ministro Sra. Araneda, quien estuvo por aprobar el referido fallo, por sus propios fundamentos y teniendo, además, en especial presente:

Primero: Que el artículo único de la Ley No 18.971, bajo el titulo de: Establece recurso especial que indica, ha creado el comúnmente denominado recurso de amparo económico, acción que deriva su apelativo del procedimiento aplicable a su tramitación;

Segundo: Que el inciso primero de dicho precepto -ya citado-prescribe que: Cualquier persona podrá denunciar las infracciones al artículo 19, número 21, de la Constitución Politica de la República de Chile; su inciso segundo dispone que el actor no necesita tener interés en los hechos denunciados y, el tercero, fija el plazo en que se debe interponer -seis meses contados desde que se hubiere producido la infracción-.

Los dos incisos finales se refieren, el primero, al recurso de apelación, y el último, a la responsabilidad por los perjuicios causados, si "se estableciere fundadamente que la denuncia carece de toda base";

Tercero: Que, como se advierte de lo ya señalado, el recurso o acción de que se trata tiene por finalidad que un tribunal de justicia compruebe la existencia de la infracción denunciada a la garantía constitucional del número 21 del artículo 19 de la Carta Fundamental, precepto que presenta dos aspectos. El primero, consistente en el derecho a desarrollar cualquiera actividad económica que no sea contraria a la moral, al orden público o a la seguridad nacional, respetando las normas legales que la regulen: y el segundo, conforme al inciso $2^{\circ}$ de esa norma, que el Estado y sus organismos pueden desarrollar actividades empresariales o participar en ellas, sólo si una ley de quórum calificado lo autoriza, inciso que, también, dispone que tales actividades estarán sometidas a la legislación común aplicable a los particulares;

Cuarto: Que es evidente que el legislador, al establecer el amparo económico en el artículo único de la Ley $N^{\circ}$ 18.971, no hizo distingo alguno en cuanto al ámbito de su aplicación. Esta garantía constitucional - a la que se le ha llamado de libre iniciativa o de libertad de empresa- es de contenido vasto, ya que comprende la libre iniciativa y la prosecución indefinida de cualquier actividad económica, sea productiva, comercial, de intercambio o de servicio, habiendo sido introducida por el Constituyente de 1980 con especial énfasis y estudio, según consta de la historia fidedigna del precepto. 
En la sesión 338 de la comisión de estudios de la nueva Constitución, se advierte esta amplitud. En efecto, en estas Actas Oficiales el señor Guzmán (...) considera válida la proposición del señor Bertelsen en cuanto a incorporar en el capitulo de las garantías constitucionales un precepto que posibilite emprender cualquier actividad económica en el campo empresarial, intimamente vinculado al derecho de propiedad privada sobre toda clase de bienes, con las excepciones que se señalan. (...). El señor Guzmán propicia, no obstante la distinción entre las formas individual y asociada, incluir en el artículo la palabra empresa que, a su juicio, tipificaría de manera muy nítida a que esta garantía como diferente de la relativa de la libertad de trabajo. (...). El señor Carmona aduce que la expresión actividad económica es muy amplia, de manera que comprende la libertad de formar todo tipo de empresas. El señor Guzmán señala que su propósito tal vez podría obtenerse con una redacción que dijese: la libertad para desarrollar cualquier actividad económica sea en forma individual o asociada...

Quinto: Que, por otra parte, no debe obviarse que la doctrina constitucional también se encuentra conteste al respecto. Sobre esta garantía-cuya protección se ampara por un recurso como el de la especie- se ha dicho que si la Constitución asegura a todas las personas el derecho a desarrollar libremente cualquier actividad económica, personalmente o en sociedad, organizadas en empresas, en cooperativas o en cualquier otra forma de asociación lícita, con el único requisito de respetar las normas que regulan la respectiva actividad (...) la obligación de no atentar en contra de la garantía no sólo se extiende al legislador, al Estado y a toda autoridad, sino también a otros particulares que actúan en el ámbito de la economía nacional. Una persona, natural o jurídica, que desarrolla una actividad económica dentro de la ley, sólo puede salir de ella voluntariamente o por ineficiencia empresarial que la lleva al cierre o a la quiebra. Pero es contraria a esta libertad, y la vulnera, el empleo por otros empresarios de arbitrios, como pactos, acuerdos, acciones y toda clase de operaciones que tengan por objeto o den o puedan dar como resultado dejar al margen de la vida de los negocios a quien esté cumpliendo legalmente una tarea en la economía del pais. (Los Derechos Constitucionales Tomo II, pág. 318).

Sexto: Que esta Corte, reiteradamente ha concluido que la acción de protección económica es plenamente procedente tratándose de ambos incisos del numeral veintiuno de la Constitución Política de la República.

Es así como ha resuelto que el recurso ampara la garantía constitucional estableciendo acción popular para denunciar todas las infracciones a dicha norma constitucional. (Causa Rol No 3899-94, C. Apelaciones de Santiago, 26 de enero de 1995). Se agrega -en esa misma resolución- que la Ley $N^{\circ} 18.971$ al establecer este recurso especial de amparo, no hizo distinción alguna entre las diversas situaciones planteadas en ambos incisos del No 21. Precisando, más aún, se ha dicho por este Tribunal que al ser una norma tan clara, la aludida ley 18.971 no se divisa de qué manera 
podría restringirse la denuncia y correspondiente indagación tan sólo a una de las dos garantias que se protegen por el indicado precepto constitucional. En efecto, no hay ninguna circunstancia que permita una interpretación diferente, en orden a que ella estaría limitada únicamente al inciso segundo de la norma de la Carta Fundamental, y cualquier otro entendimiento carece de asidero jurídico y contraría el claro sentido de la misma, que se desprende de su tenor literal. (C.S. causa Rol No 3496-03, 23 de septiembre de 2003);

Séptimo: Que, en el caso de autos, el medio impugnativo interpuesto busca proteger el menoscabo que ha sufrido el recurrente en el ejercicio de una actividad económica, al cancelársele-por parte de la Municipalidad de Santiago- la patente comercial para funcionar como taller artesanal mecánico.

El menoscabo que pueda sufrir la garantía constitucional contenida en el artículo $19 N^{\circ} 21$ en el ejercicio de cualquier actividad económica, no puede estar sujeta a limitación alguna, por lo que no puede hacerse distingo sobre sus titulares.

De esta manera, no se advierte razón por la cual fuese razonable utilizar, incluso, reglas de hermenéutica legal para introducir una restricción que el legislador no ha querido. En efecto, su intención aparece dirigida a otorgar una protección más bien general, sin discriminación alguna.

Registrese y devuélvase.

Redacción a cargo del Ministro Sr. Oyarzún y de la prevención y disidencia, sus autores.

Rol No 501-09.

Pronunciado por la Tercera Sala de esta Corte Suprema, integrada por los Ministros Sr. Adalis Oyarzún Miranda, Sr. Héctor Carreño Seaman, Sr. Pedro Pierry Arrau, Sra. Sonia Araneda Briones y Sr. Haroldo Brito Cruz. Santiago, 1 de abril de 2009. (Rol No 501-09).

Autorizada por la Secretaria de esta Corte Suprema Sra. Rosa María Pinto Egusquiza. 